\title{
Modern approaches to technology of cultivation of corn
}

\author{
Mikhail Chaplygin ${ }^{1,}$, Aliksey Podzorov ${ }^{1}$, Mariya Podzorova ${ }^{1}$, and Aigerim Alchimbayeva ${ }^{2}$ \\ ${ }^{1}$ Federal Research Agro-Engineering Center VIM, 1st Institutskiy proezd, 5, Moscow, 109428, Russia \\ ${ }^{2}$ Kazakh national agrarian university, Abay Avenue, 8, Almaty, 050010, Kazakhstan
}

\begin{abstract}
Nowadays, corn is an important source of nutrients in the human diet, as well as a valuable energy feed with the highest digestibility among cereals, a valuable raw material for the food, medical, microbiological, chemical industry and other sectors of the national economy. Increasing of corn grain production is one of the most important conditions for stabilizing the Russian food base. Being one of the technological crops that is demanding to growing conditions, corn is the most productive forage crop. It is important to note that the yield of corn depends not only on the fertility of the soil, but also on the methods of its processing and cultivation. One of the reasons holding back the growth of corn grain production is the high contamination of crops. In this paper, the influence of various cultivation technologies and methods of caring for maize crops on productivity is studied. It is shown that the highest yield and effective protection from weeds is obtained with an optimal combination of chemical and mechanical methods of crop care.
\end{abstract}

\section{Introduction}

Corn is one of the main crops in world agriculture. It plays an important role as a highly productive plant in the development of the food base. In terms of energy content, corn grain is superior to other cereals. One kilogram of it is equal to 1.34 feed units, while $1 \mathrm{~kg}$ of barley -1.26 , rye -1.18 , oats -1.0 .

On average, the grain endosperm accounts for about $70 \%$ of its weight. The endosperm of corn is white or yellow and can be powdery and vitreous (the vitreous content of corn depends on the shape of the starch grains, the density of their laying and is not associated with a higher or lower protein content). Endosperm contains a lot of starch ( $80 \%$ or more), a little protein and a small amount of fat, minerals and fiber [1].

The chemical composition of corn grain is as follows. The fat content is about $6 \%$, almost all the fat is concentrated in the germ, it is a valuable nutrient. The content of nitrogenous substances (proteins) is on average 10\% (8-12\%). Proteins are mainly represented by prolamine - zein and glutenin.

\footnotetext{
* Corresponding author: misha2728@yandex.ru
} 
Corn proteins swell poorly, do not form gluten and is not complete in amino acid composition. The main substance in corn grain is starch, the amount of which is about 60$68 \%$, is concentrated in the endosperm. Starch is a valuable substance in corn grains. Due to its high starch content, corn is successfully used for the production of starch and alcohol [1].

In addition, corn contains sugar (1.5-2.0\%), pentosans (6-8\%), minerals (2\%), fiber (2.0-2.5\%). It should be noted that the grain of white corn is low in vitamin PP and systematic nutrition of such corn causes pellagra disease. Yellow-grain varieties have more vitamin $A$ and provitamin $A$. In white-grain varieties, the content of vitamin A is reduced to a minimum. Corn grain also accumulates vitamins B1 (thiamine) and E, B2 (riboflavin), B6 (pyridoxine), PP (nicotinic acid).

Corn grain contains about $1.3 \%$ of various minerals, of which phosphorus and potassium predominate, amount of sodium, chlorine and iron is significant. More than $75 \%$ of mineral salts are concentrated in the corn germ, and the rest - in the vitreous part of the endosperm.

THE PURPOSE OF THE RESEARCH: to study the influence of various methods of processing corn crops in cultivation technology on its productivity.

\section{Materials and methods}

In the zone of the Southern Federal District (SFD), corn occupies a significant place in the crop rotation and is a good precursor for many field crops. One of the reasons holding back the growth of corn grain production is the high contamination of crops. Weeds consume a huge amount of water and nutrients from the soil. As a result of lack of moisture and nutrition, the development of the cob slows down, and infertility of plants is observed. In the presence of a large number of infertile plants, the grain yield is sharply reduced.

A significant factor in increasing crop productivity and regulating weeds is soil cultivation, of which $30-40 \%$ is spent on weed control [2].

Effective destruction of weed vegetation with a combination of mechanical and chemical methods of caring for maize crops should provide an increase in the grain yield.

At the experimental sites (Stavropol region), three variants of experiments were laid. In the first variant (Fig. 1a), agricultural equipment for culture was the basic (generally accepted) for the zone and used in many farms, including the following field operations:

- pre-emergence harrowing by MT3-82.1 + БШ-15H;

- processing of crops with Mais Ter in the normal $150 \mathrm{~g} /$ ha by unit MTZ-82.1 + Amazone UG 3000;

- the first inter-row cultivation by MT3-82.1 + KPHB-5,6-02;

- the second inter-row cultivation (chiseling) by MT3-82.1 + KPHB-5,6-02.

Maize according to the second studied option was cultivated without the use of chemical crop care products, using an herbicide-free technology (fig. 1b).

The chart of the pass-through operations looked like this:

- pre-emergence harrowing by MT3-82.1 + БШ-15H;

- harrowing on seedlings by MT3-82.1 + БШ-15H;

- the first inter-row cultivation by MT3-82.1 + KPHB-5,6-02;

- the second inter-row cultivation by MT3-82.1 + KPHB-5,6-02;

- the third inter-row cultivation with hilling by MT3-82.1 + KPHB-5,6-02.

The third option of the experiment is the cultivation of corn using herbicide technology. The list of technological operations in this version was as follows:

- pre-emergence harrowing by MT3-82.1 + БШ-15H;

- harrowing on seedlings by MT3-82.1 + БШ-15H; 
- processing of crops with the preparation Sekator turbo in the norm of $100 \mathrm{~g} / \mathrm{ha}$ by the MT3-82.1 + Amazone UG 3000;

- the first inter-row cultivation by MT3-82.1 + KPHB-5,6-02;

- the second inter-row cultivation by MT3-82.1 + KPHB-5,6-02;

- the third inter-row cultivation with hilling by MT3-82.1 + KPHB-5,6-02.

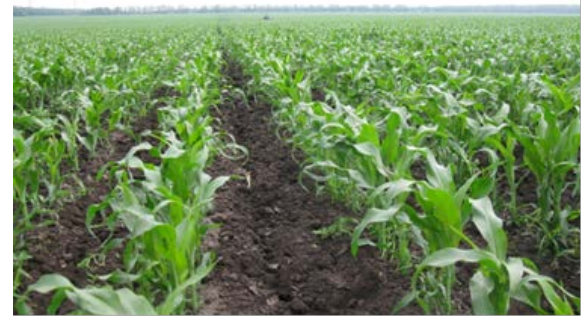

a

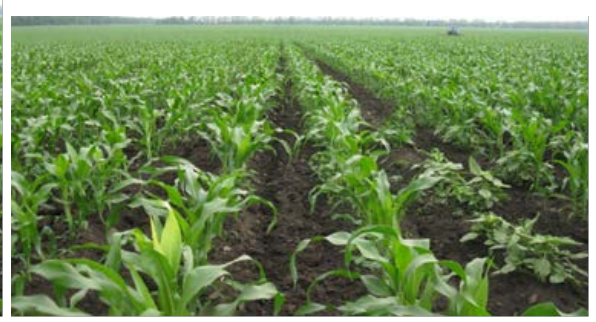

b

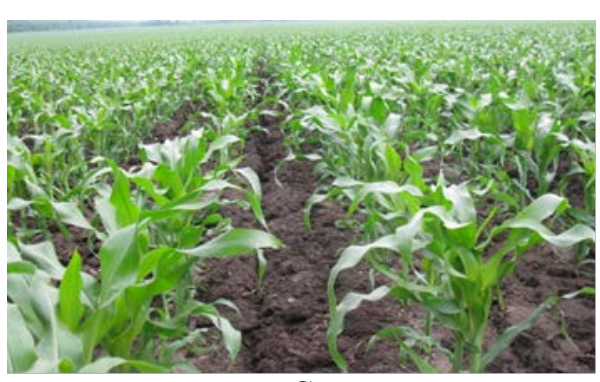

C

Fig. 1. The variants of the experiments on cultivation of maize: a - №1, b - №2, c - №3.

The soil of the experimental site belongs to typical chernozems, medium-humus, heavyloam, which are characterized by high agricultural advantages.

Humus is an organic substrate containing a large amount of nitrogen and other trace elements useful for plants. According to its amount, soils are divided into: low-humus, moderate-humus, medium-humus and humus. Thus, the soil of the experimental site is quite fertile.

\section{Results and discussion}

The main environmental factors that limit the yield of corn and the possibility of its cultivation in certain areas are heat and moisture [3]. The higher the heat supply, the more noticeable the advantage of corn in relation to other crops. Lack of moisture in the soil at any stage of development of maize plants leads to a decrease in productivity [3].

Seeding of the zoned hybrid Ladoga $250 \mathrm{MV}$ was carried out in the recommended agroterms when the soil was warmed up to $10-12^{\circ} \mathrm{C}$ with an established seeding rate of 5.2 pieces per 1 running meter. The density of standing plants in crops should be optimal, this is a guarantee of a higher grain yield, even if there is a lack of moisture in the soil. The seeding scheme is single-line, with a row spacing of $70 \mathrm{~cm}$. Weather conditions during the establishment of trials as a whole was typical for the area. The initial soil moisture at the time of sowing in layers from 0 to $15 \mathrm{~cm}$ was in the range of 31.5-35.5\%, which contributed to the rapid and friendly emergence of seedlings. The average number of vegetating weeds in the experimental field was $125 \mathrm{PCs} / \mathrm{m} 2$ with an average height of $2 \mathrm{~cm}$. Pre-sowing cultivation allowed to free the field from weeds by $100 \%$.

Stage of tests:

1. on all variants of the experiment, pre-emergence harrowing of crops was carried 
out in order to destroy the soil crust and destroy weeds. Before this operation, the average number of weeds on the plots was $3.5 \mathrm{PCs} / \mathrm{m} 2$. Then, after 20 days, the crops of option 1 were processed with the herbicide Mais Ter (dose $150 \mathrm{~g} / \mathrm{ha}$ ).

Control of weeds in the corn field was carried out with a universal post-crop herbicide Master (0.25-0.15 l/ha), for the control of annual, perennial monocotyledonous, dicotyledonous and cereal weeds. Spraying of crops 3-5 maize leaves and early stages of weed growth in a mixture of 1 l/ha of Biopower adjuvant, VRK (276.5 g/l), working fluid consumption - $200 \mathrm{l} / \mathrm{ha}$.

1. In the 2nd and 3rd variants of the experiment was carried out harrowing on shoots.

We conducted the first inter-row cultivation in the second version of the experiment. Option 3 crops were processed with Secator turbo.

2. The first inter-row cultivation was carried out in the 1st and 3rd variants,

and the second inter-row cultivation in the 2nd variant of the experiment. By this time, the number of cultivated plants in the accounting frame with an area of $0.25 \mathrm{~m} 2$ was according to the options, respectively: 189.5 PCs.; 183.0 PCs.; 186 PCs.

3. In the 3rd version of the experiment, a second inter-row cultivation with chiseling

was carried out. The second inter-row cultivation with chiseling in the 1st variant and the third inter-row cultivation with hilling in the 2nd and 3rd variants were carried out.

After inter-row and chemical processing of crops in experimental plots, the height of cultivated plants was determined and the corn weeds were accounted for. Table 1 shows the dynamics of maize and weeds development depending on the methods of crop care.

Table 1. Development of cultural and weed plants in the variants of experiment

\begin{tabular}{|l|l|l|l|l|l|l|l|l|l|}
\hline Stage & \multicolumn{3}{|l|}{$\begin{array}{l}\text { The height of cultivated } \\
\text { plants, cm }\end{array}$} & \multicolumn{3}{ll}{ Height of weeds, cm } & \multicolumn{2}{l|}{ Number of weeds, PCs/m2 } \\
\hline & №1 & №2 & №3 & №1 & №2 & №3 & №1 & №2 & №3 \\
\hline 1 & 13,5 & 13,3 & 14,8 & - & - & - & 0 & 32,5 & 28,2 \\
\hline 2 & 44,7 & 40,8 & 46,6 & - & - & - & 10,6 & 13,8 & 10,3 \\
\hline 3 & 158,0 & 126,2 & 135,1 & 22,1 & 72,4 & 26,2 & 16,0 & 20,4 & 13,3 \\
\hline 4 & 312,9 & 297,4 & 300,9 & 35,2 & 127,8 & 40,2 & - & - & - \\
\hline
\end{tabular}

Note: № 1-basic technology; № 2-herbicide-free technology; № 3-herbicide technology.

Table 1 shows that the size and number of weeds in the herbicide-free version is greater than in other areas. Among weeds, dicotyledonous plants dominated, mainly tilted schiritsa (amaranth), and spreading quinoa, which were 1.5-2 times more than cereals (setaria glauca). Corn harvesting in the studied areas was carried out with a grain harvester ACROS 580 (Fig. 2).

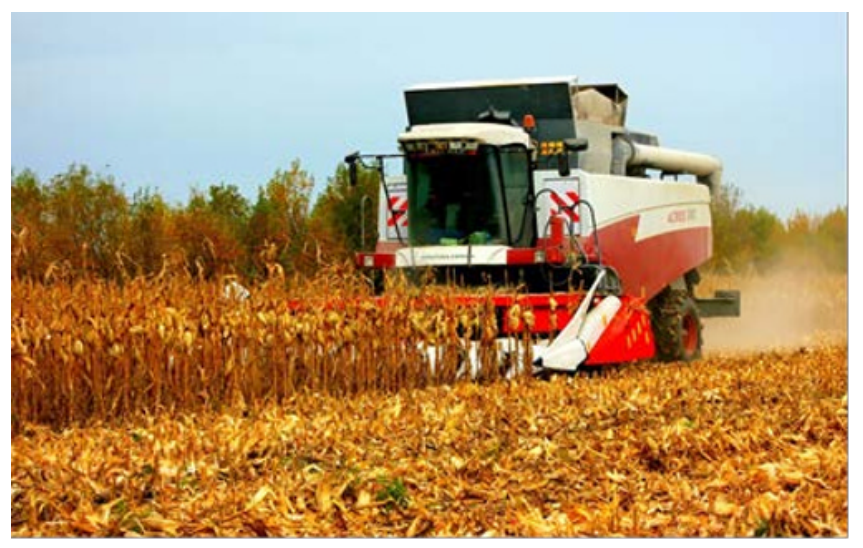

Fig. 2. Corn harvester "CornMaster 8" in the unit with the ACROS 580 combine. 
Indicators that characterize the conditions and quality of cleaning are shown in table 2. From the numerical data shown in table 2, it can be seen that the care of crops using only a single row cultivation operation did not provide proper removal of weeds and, as a result, the presence of a large number of weeds in corn crops caused a decrease in the mass and density of cultivated plants, which caused a decrease in productivity.

Table 2. Characteristics of maize plants and yield at the time of harvesting

\begin{tabular}{|l|l|l|l|}
\hline & №1 & №2 & \multicolumn{1}{|c|}{ №3 } \\
\hline Plant density, thousand units / ha & 68,8 & 58,3 & 60,2 \\
\hline Plant height, cm & 312,9 & 297,4 & 300,9 \\
\hline Stem diameter, mm & 20,6 & 19,3 & 19,6 \\
\hline The height of the bottom of the cob, cm & 142,8 & 135,4 & 137,5 \\
\hline Cob length, cm & 18,5 & 16,2 & 16,7 \\
\hline The diameter of the cob, mm & 44,5 & 40,2 & 41,3 \\
\hline The ratio of grain mass to the mass of the non-grain part & $1: 1,0$ & $1: 1,1$ & $1: 1,0$ \\
\hline Humidity, \%: & & & \\
\hline -seeds & 10,4 & 11,8 & 10,4 \\
\hline - non-grain part & 9,7 & 10,2 & 9,7 \\
\hline Yield, C/ha & 71,4 & 62,0 & 62,8 \\
\hline
\end{tabular}

\section{Conclusions}

As a result of the research, it was noted that the highest yield (71.4 C/ha) was obtained from the base background. When corn was cultivated without the use of chemical weed control measures, the crop yield was $62.0 \mathrm{C} / \mathrm{ha}$. According to the herbicide technology, the yield increase was $0.8 \mathrm{C} /$ ha compared to the herbicide-free one. However, three-fold cultivation of row spacing together with the use of chemical methods of care did not contribute to energy conservation.

Thus, the optimal combination of chemical and mechanical methods of care (in our case, this is the basic technology) contributed to more effective protection of corn plants from weeds and allowed to get a high yield.

\section{References}

1. Wang H., J.-s. Liu, W.-h. Min, M.-z. Zheng, H. Li, J. of Integr. Agric., 18(11) 26442651 (2019)

2.K Carruthers, Q Fe, D Cloutier, D. L Smith, Europ. J. of Agron. 8 (3) 225-238 (1998)

3. N. Strom, W. Hu, D. Haarith, S. Chen, K. Bushley Appl. Soil Ecol. 147103388 (2020) 